\title{
Kvinne med høyt oksygeninnhold i sentralvenøs blodgass
}

\author{
Hos kritisk syke brukes ofte sentralvenøs oksygenmetning som en \\ indikator på om oksygenforsyningen tilfredsstiller organismens behov. \\ Ved sirkulasjonssvikt er lav sentralvenøs metning vanlig, men hvordan \\ forklarer vi en svært høy metning?
}

En kvinne i slutten av 40-årene i svært redusert allmenntilstand ble innlagt på kirurgisk avdeling ved et universitetssykehus etter en uke med mageplager, kvalme og oppkast. Hun hadde kjent anorexia nervosa fra barneårene, lettgradig astma/kronisk obstruktiv lungesykdom (kols) og var tidligere opioidmisbruker. Det var registrert flere innleggelser på grunn av funksjonssvikt, dårlig ernæringsstatus og kramper av ukjent årsak $i$ løpet av de siste seks årene. Hun hadde ikke vært utendørs på minst $1 / 2$ år da hun ble lagt inn.

Ved innkomst var hun i redusert allmenntilstand, febril med temperatur $38,1^{\circ} \mathrm{C}$ og takykard med puls 120/minutt. Ved auskultasjon var det normale forhold over cor og knatring over basale lungeflater. Abdomen var diffust $\emptyset m$ ved palpasjon. CRP var $205,3 \mathrm{mg} / \mathrm{l} / 0,0-4,0$ $\mathrm{mg} / \mathrm{l}), \mathrm{Hb}$ var $10,6 \mathrm{~g} / 100 \mathrm{ml}(11,7-15,3 \mathrm{~g} /$ $100 \mathrm{ml}, \mathrm{Na}^{+} 132 \mathrm{mmol} / \mathrm{l}(137-145 \mathrm{mmol} / \mathrm{l})$, $\mathrm{K}^{+} 2,5 \mathrm{mmol} / \mathrm{l}(3,6-4,6 \mathrm{mmol} / \mathrm{l})$ og albumin $23 \mathrm{~g} / \mathrm{l}(36-45 \mathrm{~g} / \mathrm{ll}$. Øvrige blodprøver var stort sett normale.

Initialt mistenkte man subileus. CT abdomen viste ingen fri luft eller mistanke om passasjehinder, men ga mistanke om kolitt $i$ høyre fleksur. Lavattenuerte områder i nedre miltpol ga mistanke om miltinfarkter. Cefuroksim og metronidazol ble gitt på bakgrunn av uavklart buk og forhøyede infeksjonsprøver. På grunn av vanskelig perifer intravenøs tilgang ble et sentralt venekateter (SVK) lagt inn via høyre vena subclavia. Røntgen thorax etter innleggelse viste korrekt posisjon med spissen dypt i vena cava superior. Pasienten fallerte ytterligere, koloskopi viste mulig iskemisk kolitt, og hun ble seks dager senere overført til medisinsk avdeling. Da hun var svært medtatt og klinisk dehydrert med vedvarende elektrolyttforstyrrelser, ble hun lagt på medisinsk intensiv- og overvåkingsavdeling.

Behandlende leger mistenkte endokarditt på bakgrunn av infeksjonstegn og mulige septiske embolier til milt og tarm.

Ved ankomst intensiv- og overvåkingsavdelingen var hun takykard med puls på 120/ min og respiratorisk besværet med arteriell $\mathrm{O}_{2}$-metning målt pulsoksymetrisk $\left(\mathrm{SpO}_{2}\right)$ på rundt $90 \%$ (referanseverdi 94-99\%) med 10 l $\mathrm{O}_{2}$ på maske. For å få bedre oversikt over sirkulasjonsstatus tok man en blodgass fra det sentrale venekateteret. Svaret viste, noe overraskende, en sentralvenøs metning $i$ blod fra v. cava superior $\left(\mathrm{ScvO}_{2}\right)$, som var så å si identisk med metningen $i$ en samtidig tatt arteriell blodgass fra arteria radialis. $\mathrm{ScvO}_{2}$ var $92,5 \%$ (referanseverdi $72-78 \%$ ) og arteriell oksygenmetning 93,3\% (referanseverdi 92-99\%). Kontrollprøve av blodgass fra det sentrale venekateteret analysert på en annen maskin viste tilsvarende verdi.

Nesten alt oksygenet i blodet (normalt ca. $98,5 \%$ ) er bundet til hemoglobin. Hemoglobinkonsentrasjon og oksygenmetning reflekterer derfor i de fleste situasjoner blodets oksygeninnhold. En økning av sentralvenøs metning i forhold til normalverdien ses ved tilstander der oksygenforsyningen øker mer enn forbruket, der oksygenforbruket er redusert uten tilsvarende reduksjon av forsyningen, eller en kombinasjon av begge deler. Ved normal aerob metabolisme i hvile vil ca. $25 \%$ av blodets oksygeninnhold, eller $200-250 \mathrm{ml} / \mathrm{min}$, ekstraheres fra blodet. Gjennomsnittsmetningen i blod fra alle kroppens organer (blandet venøst blod $\left.\left(\mathrm{S}_{\mathrm{V}} \mathrm{O}_{2}\right)\right)$ er derfor normalt rundt $75 \%(1,2)$. $\mathrm{S}_{\mathrm{V}} \mathrm{O}_{2}$ måles i prøver tatt fra det distale løpet $i$ et kateter i lungearterien (arteria pulmonalis). Bruken av disse er generelt i nedgang (3). Derimot har mange pasienter et sentralt venekateter, som gjør det mulig å måle sentralvenøs metning i v. cava superior. Prøver tatt fra et slikt kateter reflekterer oksygenbalansen i overkroppen og ikke i hele organismen. Hvorvidt slik måling kan brukes som et surrogat for måling $\mathrm{i}$ blandet venøst blod, $\mathrm{SvO}_{2}$, er derfor omdiskutert $(1,3,4)$.

En dobling av oksygenforsyningen ved å doble hjerteminuttvolumet vil øke $\mathrm{SvO}_{2}$ til ca. $85 \%$. Slike verdier kan ses hos pasienter i vasodilatatorisk (ofte septisk) sjokk. Ved enkelte sjeldne tilstander, deriblant noen genetiske sykdommer og forgiftninger (eksem-

\author{
Tuva Matheson Hegna \\ tuvamh@gmail.com \\ Akuttklinikken \\ Oslo universitetssykehus, Rikshospitalet \\ Eirik Qvigstad \\ Hjertemedisinsk avdeling \\ Nils-Einar Kløw
}

Enhet for thorax-, kar- og intervensjonsradiologi

\section{Helge Opdahl}

Akuttmedisinsk avdeling

Oslo universitetssykehus, Ullevål

IV

Engelsk oversettelse på www.tidsskriftet.no 
pelvis cyanid), kan $\mathrm{O}_{2}$-forbruket være sterkt redusert pga. mitokondriedysfunksjon. $\mathrm{SvO}_{2}$ kan i slike tilfeller være mye høyere enn klinisk tilstand skulle tilsi. Man vil imidlertid se økt melkesyreproduksjon med stigning av laktat i blodet, som tegn på anaerob metabolisme.

Ved overflyttingen var pasienten afebril, hadde en hemoglobinverdi på 9,2 g/dl og normalt laktatnivå på $0,9 \mathrm{mmol} / \mathrm{l}$ (referanseverdi 0,4-2,2 $\mathrm{mmol} / \mathrm{ll}$.

Siden pasienten var afebril og hadde normalt laktatnivå, var septisk sjokk og mitokondriedysfunksjon lite sannsynlig. Andre årsaker til en svært høy $\mathrm{SvO}_{2}$ kan være kateter i feil posisjon (enten arterielt eller med spissen perforert til arterie/lungevene/venstre hjertehalvdel) og anatomiske forhold hos pasienten som gir en venstre-til-høyre-shunt der åpningen fra kateterets lumen ligger $\mathrm{i}$ en venstre-til høyre-jetstrøm (åpent foramen ovale, sentrale arteriovenøse shunter).

Muligheten for at spissen på det sentrale venekateteret likevel kunne ligge arterielt, ble avkreftet ved ny granskning av røntgen thorax-bildet samt at elektronisk trykkmåling via kateterlumen viste venøse trykknivåer.

På grunn av fortsatt mistanke om endokarditt fant man indikasjon for transøsofageal ekkokardiografi. Ettersom pasientens respirasjon var marginal, ble hun intubert $i$ forkant av undersøkelsen. Det ble påvist middels til stor aortainsuffisiens, og aortaendokarditt med avgåtte vegetasjoner kunne ikke utelukkes. Man fant ingen atrieseptumdefekt (ASD), ventrikkelseptumdefekt (VSD) eller åpent foramen ovale.

Til tross for at man var rimelig sikker på at det sentrale venekateteret var riktig plassert, valgte man dagen etter overflytting til intensiv- og overvåkingsavdelingen å legge et nytt, nå med innstikk i høyre vena jugularis. Også dette ble ved røntgenkontroll funnet å ligge i riktig posisjon. Blodgasser tatt fra det distale løpet var imidlertid nesten tilsvarende de tatt dagen før $1 \mathrm{ScvO}_{2} 91 \%$ og $87 \%$, mens tilsvarende $\mathrm{SaO}_{2}$ var $93,8 \%$ og $90,3 \%$ ). Parallelle prøver tatt fra det distale og det proksimale løpet (avstand $6 \mathrm{~cm}$ ) noen dager senere viste $h h v .85,8 \%$ og $78, \%$, dvs. en forskjell på nesten $8 \%$.

Varierende verdier kan tyde på at blodet $\mathrm{i}$ v. cava superior er sjiktet og ikke ordentlig blandet, slik at lokalisasjonen for prøvetaking kan ha stor betydning for resultatet.

Pasienten ble respiratorbehandlet $i$ totalt åtte døgn pga. respirasjonssvikt. Hun ble på overvåkingsavdeling ytterligere seks dager

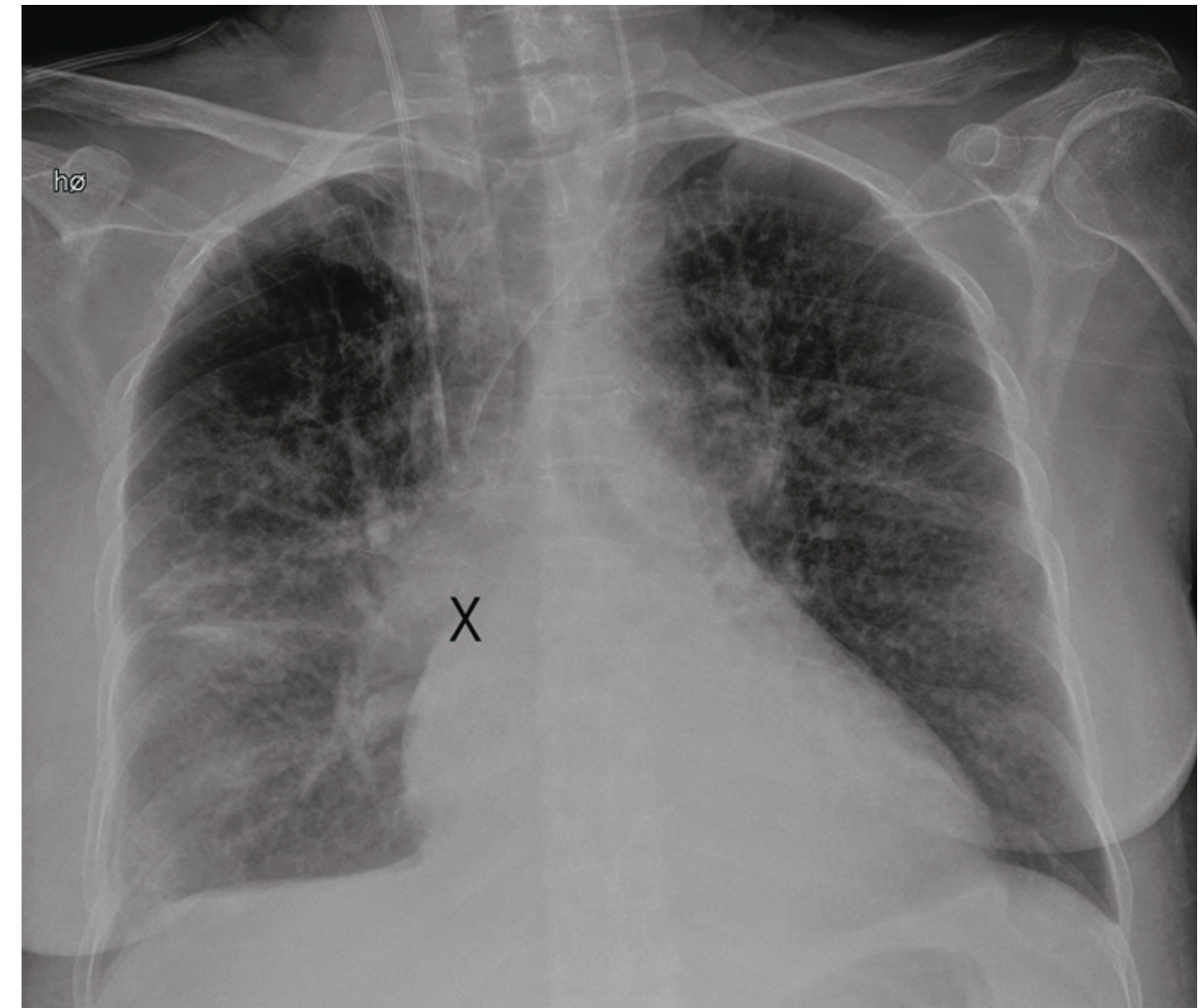

Figur 1 Røntgenbilde som viser posisjon av sentralt venekateter nr. 2 og nr. 3. Posisjon av spissen på nr. 1 (fra tidligere bilder) er markert med et kryss

pga. svært dårlig allmenntilstand og utvikling av hjertesvikt med dyspné, pleuravæske og deklive ødemer. Ved overflytting til sengepost var hun fortsatt kraftløs og med behov for parenteral ernæring. Flere kirurgiske tilsyn og bildediagnostikk konkluderte med paralytisk ileus. På sengepost ble det pga. rubor rundt innstikkstedet lagt et nytt sentralt venekateter. Første forsøk på innstikk, nå via venstre v. jugularis interna, ble avbrutt fordi anestesilegen fikk lyst rødt blod tilbake ved aspirasjon og antok at han hadde kommet inn $i$ en arterie. Nytt innstikk ble gjort under ultralydveiledning, og man så da ingen spor etter blødning fra eventuell perforasjon av arterie. I ettertid er det rimelig å anta at også første forsøk var vellykket, men at uventet aspirasjon av arterielt farget blod ble feiltolket av en lege som ikke kjente til pasientens forhistorie. Blodprøver tatt fra dette tredje kateteret, der spissen vurdert røntgenologisk lå på samme sted som nr. 2 (fig 1), viste vedvarende tilnærmet identiske verdier venøst som prøver tatt arterielt, rundt $95 \%$. Pasienten ble derfor henvist til CT angiografi for å avklare mistanken om sentral arteriovenøs shunt. Undersøkelsen påviste en sjelden anatomisk anomali der venstre pulmonalvenes ene gren drenerte direkte til tverrvenen, vena brachiocephalica sinistra (fig 2, fig 3). Det var gjennom innleggelsen tatt flere røntgen thorax, men ingen
Tabell 1 Blodgasser tatt via det tredje sentralvenøse kateteret ved uttrekk av kateteret, fra distalt (dypt i vena cava superior) $\left(\mathrm{ScvO}_{2}\right)$ til innstikkstedet lvenstre vena jugularis internal, med duplikatverdi i parentes. Ut ifra beregninger av kateterposisjon under uttrekksprosedyren tilsvarer prøven $8 \mathrm{~cm}$ fra utgangsposisjon, lokalisasjon av kateterspissen ved innmunningen av lungevenen til tverrvenen (se figur 2)

\begin{tabular}{lc}
$\begin{array}{l}\text { Beliggenhet } \\
\text { av kateterspiss }\end{array}$ & $\begin{array}{c}\mathrm{ScvO}_{2} \text { (dublikat- } \\
\text { verdi) }(\%)\end{array}$ \\
$\begin{array}{l}\text { Utgangsposisjon } \\
\text { i v. cava superior }\end{array}$ & $80,8(80,9)$ \\
$-2 \mathrm{~cm}$ & $77,6(78,2)$ \\
$-4 \mathrm{~cm}$ & $80,4(80,6)$ \\
$-6 \mathrm{~cm}$ & $56,5(57,6)$ \\
$-8 \mathrm{~cm}$ & $91,7(89,3)$ \\
$-10 \mathrm{~cm}$ & $66,8(67,1)$ \\
$-12 \mathrm{~cm}$ & $51,4(52,5)$ \\
\hline
\end{tabular}




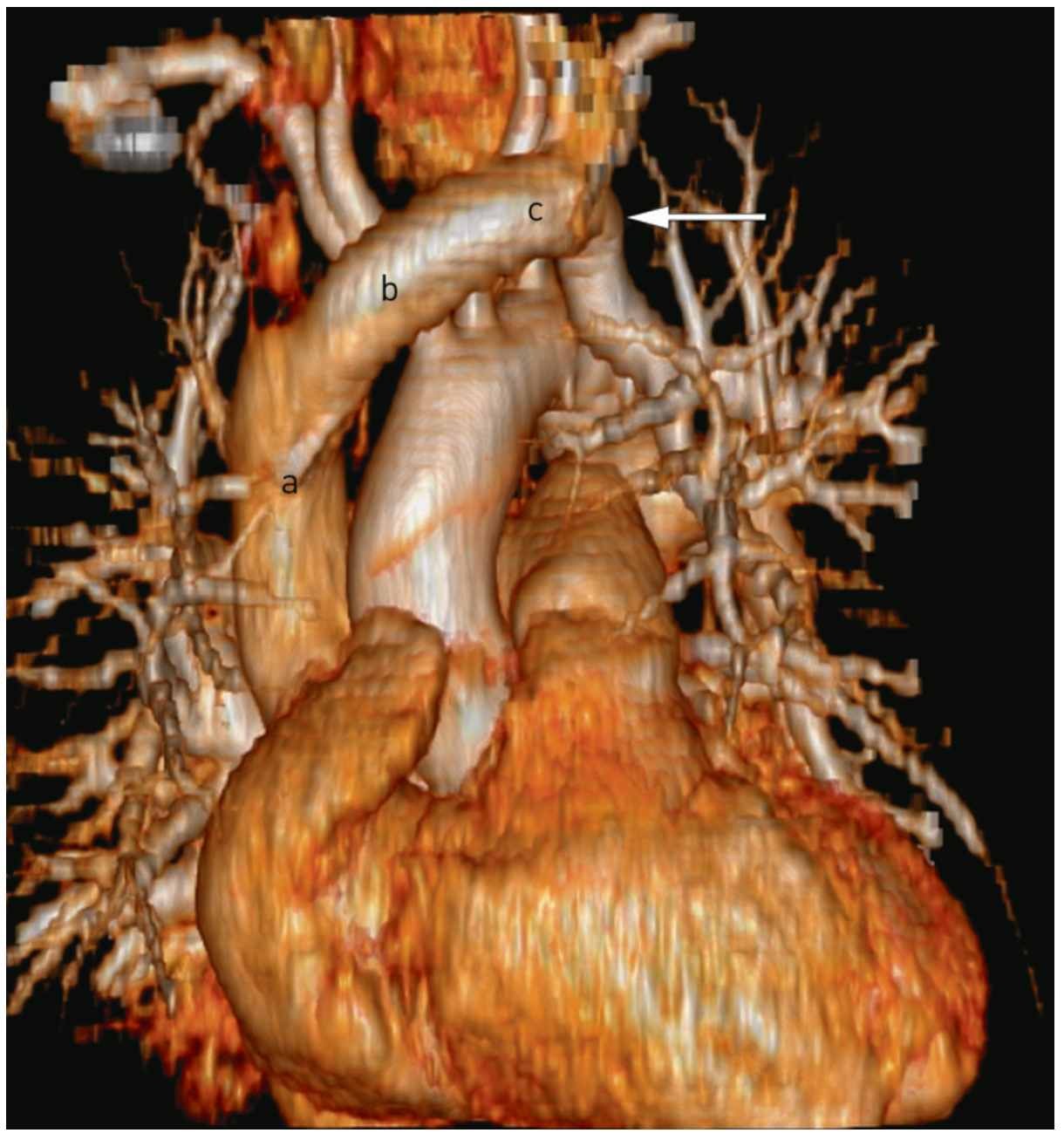

Figur 2 Modell av hjertet og de store kar hos pasienten, rekonstruert etter CT angiografi-undersøkelsen. Innløpet av venstre pulmonalvenes ene gren til tverrvenen, vena brachiocephalica sinistra, er markert med pil. a,b og c tilsvarer blodgasser tatt via det tredje sentralvenøse kateteret ved uttrekk av kateteret, hhv. utgangsposisjon, etter $4 \mathrm{~cm}$ og $8 \mathrm{~cm}$ (jf. tab 1)

av disse kunne gi mistanke om en slik anomali.

Anomalien fører til at godt oksygenert blod fra lungen dreneres inn til venesystemet. Funksjonelt tilsvarer dette oksygeneringsmessig en stor venstre-til-høyre-shunt, noe som forklarte funnet av flere tilnærmet like $\mathrm{SO}_{2}$-verdier i arteriell og venøs blodgass.

Ved revurdering av tidligere ekkobilder (både transøsofageale og transtorakale), fant man på grunnlag av beregning av minuttvolum fra henholdsvis høyre og venstre ventrikkel at høyre ventrikkels minuttvolum lå ca. $34 \%$ over venstre ventrikkels. I tillegg så man antydning til forhøyet trykk i høyre ventrikkel med avflating av septum i diastolen. CT-bildene viste også en dilatert venstre $v$. brachiocephalica med diameter $18 \mathrm{~mm}$, som er ca. $50 \%$ større enn normaldiameter. Dette stemmer bra med vesentlig øket strøm gjennom karet.
Partiell, avvikende pulmonalvenekobling (partial anomalous pulmonary venous connection, PAPVC) er en sjelden, medfødt anomali, med insidens på $0,4-0,7 \%(5,6)$. Anomalien innebærer oftest at en (eller flere) pulmonalvene(r) er koblet til høyre atrium eller v. cava i stedet for til venstre atrium, slik at oksygenert blod strømmer tilbake til høyresiden, dvs. analogt med en venstre-til-høyre-shunt på hjertenivå. Isolert partiell, avvikende pulmonalvenekobling (uten atrieseptumdefekt) er en sjelden tilstand, og innebærer oftest at øvre høyre pulmonalvene drenerer til v. cava superior. Anomalien som vår pasient hadde, med affeksjon av venstre pulmonalvene med drenasje til venstre v. brachiocephalica, affiserer ca. $3 \%$ av alle med partiell, avvikende pulmonalvenekobling (5). Således er dette en svært sjelden anomali. Symptombildet er avhengig av hvor mange pulmonalvener som drenerer til høyresiden av hjertet. En enkelt avvikende vene er sjelden av hemodynamisk betydning og gir dermed oftest ingen sympto- mer (5), men representerer likevel en økt belastning på høyre ventrikkel.

Da det sentrale venekateteret skulle seponeres, ble det tatt duplikate, sentralvenøse blodgasser for annenhver centimeter vi trakk kateteret. Dette for å se hvordan den sentralvenøse metningen endret seg avhengig av posisjon på kateteret i forhold til innmunningen av anomalien. Totalt ble det tatt sju prøver (tab 1). $\mathrm{SpO}_{2}$ var da $92-94 \%$ med $3 \mathrm{lO}_{2}$ på nesegrime.

På bakgrunn av stor aortainsuffisiens og destruksjon av en av aortacuspene ble pasienten behandlet for antatt stafylokokkendokarditt med empirisk antibiotika. Det var imidlertid ingen funn i gjentatte blodkulturer, og man fant heller ingen vegetasjoner eller pendulering ved gjentatte ekko-undersøkelser. Den partielle avvikende pulmonalvenekoblingen ga ingen åpenbare kliniske, hemodynamiske konsekvenser. Aortainsuffisiensen var i seg selv alvorlig nok til at det kunne være operasjonsindikasjon. Etter en tverrfaglig vurdering avslo man kirurgi pga. vesentlig komorbiditet, ernæringsvansker, pågående feber og usikker rehabiliteringsevne. Pasienten var ved utskrivning fortsatt pleietrengende og ble utskrevet til sykehjem etter knappe to måneders innleggelse.

\section{Diskusjon}

Oksygenmetning i blandet venøst blod, $\mathrm{SvO}_{2}$, sier noe om forholdet mellom oksygenforsyningen og oksygenforbruk i organismen. Oksygenforsyningen er avhengig av hjertets minuttvolum, arteriell oksygenmetning samt hemoglobinnivå. Forbruket er relatert til blant annet kroppstemperatur, muskelaktivitet og hormonelle faktorer. Økt oksygenforbruk vil normalt kompenseres helt eller delvis med økt hjerteminuttvolum. Synkende $\mathrm{SvO}_{2}$ kan være tegn på økt oksygenforbruk uten tilstrekkelig sirkulatorisk kompensasjon, eller at $\mathrm{O}_{2}$-tilførselen er kompromittert (for eksempel ved hjertesvikt). Vedvarende lave verdier er assosiert med vevshypoksi og laktatutvikling. Man har ved hjertekirurgi sett en grense på $55 \%$, der verdier under dette medførte høyere mortalitet og forlenget intensivopphold (7). Normale eller supranormale verdier garanterer imidlertidig ikke adekvat vevsoksygenering, idet man for eksempel kan se høye $\mathrm{SvO}_{2}$-verdier ved arteriovenøs shunting eller når vevet ikke klarer å ekstrahere oksygen pga. mitokondriedysfunksjon (forgiftning, sykdom) eller celledød.

Det første kateteret lå lengst distalt i v. cava superior, slik at man kunne tenke seg at kraftig refluks fra en atrieseptumdefekt kunne gi den høye $\mathrm{ScvO}_{2}$-verdien De to neste katetrene lå imidlertid mer proksimalt i v. cava superior, og en høy sentralvenøs metning herfra kan vanskelig forklares av en slik årsak (fig 1). 

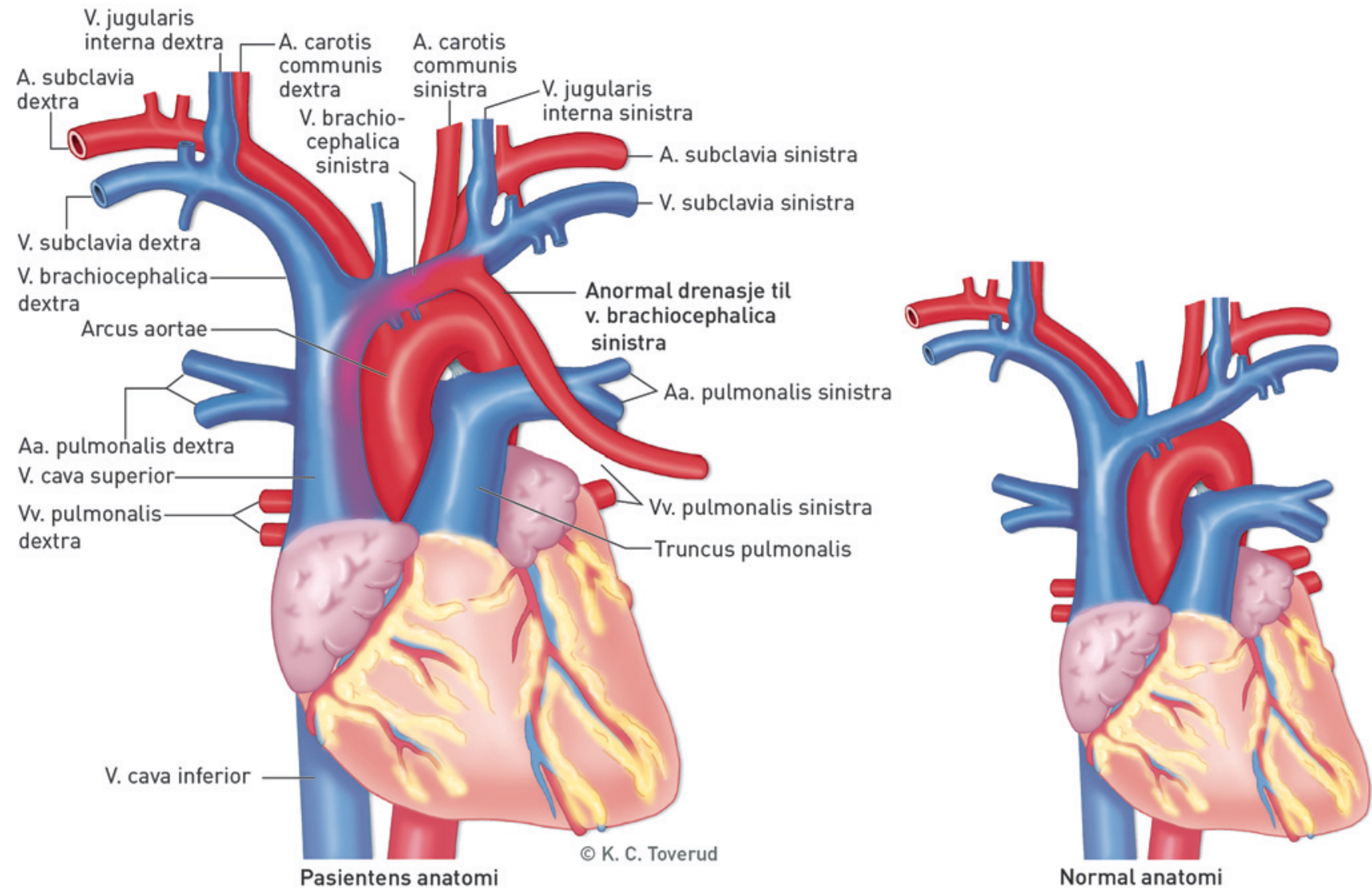

Figur 3 Normal anatomi og pasientens anatomi

Pasienten hadde en sjelden, medfødt karanomali. Partiell, avvikende pulmonalvenekobling gir sjelden symptomer før voksen alder. Økt strøm til høyresiden av hjertet kan medføre pulmonal hypertensjon, høyre ventrikkel-dysfunksjon, arytmier og trikuspidalinsuffisiens (5). Hos vår pasient påviste man øt høyrebelastning. Påvirkning av høyresiden av hjertet kan gi symptomer som utmattelse/fatigue, dyspné og redusert fysisk ytelse. Dette kan være en av faktorene som bidro til den dårlige allmenntilstanden. Hun hadde samtidig betydelig komorbiditet (anorexia nervosa og tidligere opioidmisbruk), som vel så gjerne kan forklare hennes fysiske reduksjonsnedsettelse.

Det finnes lite data vedrørende mortalitet og morbiditet av partiell, avvikende pulmonalvenekobling (5), da de fleste påviste tilfeller er tilfeldige funn. Den endelige behandlingen er kirurgi, men indikasjonen er omdiskutert. Noen mener man bør opereres som barn for å unngå utvikling av eventuelle komplikasjoner, siden kirurgien har lav mortalitet og morbiditet. Andre mener det ikke er indikasjon før man har en symptomatisk shunt (5).
Hos vår pasient fikk vi et uventet og overraskende prøvesvar da vi tok blodgass fra sentral vene. Den første refleksjonen var at svaret måtte være galt, noe som medførte ny blodprøve. Svaret på denne, analysert på en annen maskin, var identisk med den første. Det var deretter nærliggende å tro at kanylen lå arterielt, noe som ville kunne ha alvorlige konsekvenser for pasienten. Arteriell beliggenhet ble avkreftet. I dette tilfellet tok det flere uker før man fikk gjort videre undersøkelser som kunne kartlegge årsaken til den vedvarende høye $\mathrm{S}_{\mathrm{CV}} \mathrm{O}_{2}$-verdien. En av grunnene kan være at pasienten ble flyttet mellom flere ulike avdelinger med forskjellige fokus og at det ikke var gode nok rutiner for videre oppfølging.

Videre bildediagnostikk kartla altså årsaken til en uventet, høy sentralvenøs metning. Ved henvisning til CT var det viktig å spesifisere symptomer og kliniske funn, slik at radiologene hadde optimale forutsetninger for god diagnostikk. Funnet var såpass sjeldent at det lett kunne overses i en hektisk hverdag, der det vanligste tross alt er vanligst. Den definitive diagnostikken fikk ingen praktiske konsekvenser for pasienten, men kunne ha fått stor betydning hvis man hadde valgt å operere aortainsuffisiensen hennes.

Pasienten har samtykket til at artikkelen blir publisert.

\section{Tuva Matheson Hegna (f. 1978)}

er lege i spesialisering i anestesiologi. Forfatter har fylt ut ICMJE-skjemaet og oppgir ingen interessekonflikter.

\section{Eirik Qvigstad (f. 1972)}

er ph.d. og lege i spesialisering i kardiologi. Forfatter har fylt ut ICMJE-skjemaet og oppgir ingen interessekonflikter.

\section{Nils-Einar Kløw (f. 1954)}

er dr.med., spesialist i radiologi, intervensjonsradiolog og enhetsleder. Han er professor ved Universitetet i Oslo.

Forfatter har fylt ut ICMJE-skjemaet og oppgir ingen interessekonflikter. 


\section{Helge Opdahl (f. 1942)}

er dr.med. og spesialist i anestesiologi. Han har bred erfaring fra akutt- og intensivmedisin, særlig innen hemodynamikk og oksygentransport og har ledet Nasjonal behandlingstjeneste for CBRNemedisin (medisinsk behandling ved stråle-/radioaktive, biologiske og kjemiske hendelser). Forfatter har fylt ut ICMJE-skjemaet og oppgir ingen interessekonflikter.

\section{Litteratur}

1. van Beest P. Wietasch G, Scheeren T et al. Clinical review: use of venous oxygen saturations as a goal - a yet unfinished puzzle. Crit Care 2011; 15: 232.

2. Rivers EP, Ander DS, Powell D. Central venous oxygen saturation monitoring in the critically ill patient. Curr Opin Crit Care 2001; 7: 204-11.

3. Walley KR. Use of central venous oxygen saturation to guide therapy. Am J Respir Crit Care Med 2011; 184: 514-20.

4. Kopterides P, Bonovas S, Mavrou I et al. Venous oxygen saturation and lactate gradient from superior vena cava to pulmonary artery in patients with septic shock. Shock 2009; 31: $561-7$

5. Medscape. Partial Anomalous Pulmonary Venous
Connection, Jul 27 2012. http://emedicine. medscape.com/article/897686-overview (5.1.2014).

6. Nath R, Murphy W, Aronson B. Rare case of left upper lobe partial anomalous pulmonary venous connection. J Radiol Case Rep 2013; 7: 9-14.

7. Svedjeholm R, Håkanson E, Szabó Z. Routine SvO2 measurement after CABG surgery with a surgically introduced pulmonary artery catheter. Eur J Cardiothorac Surg 1999; 16: $450-7$

Mottatt 3.7. 2014, første revisjon innsendt 24.11. 2014, godkjent 1.4. 2015. Redaktør: Siri Lunde Strømme. 